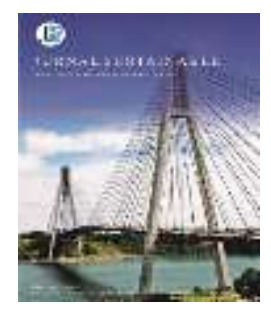

\title{
Prototipe Penerapan Internet of things pada Sistem Informasi Penggunaan Air Rumah Tangga Di BLUD UPT SPAM Kabupaten Musi Rawas
}

\author{
M. Agus Syamsul Arifin ${ }^{1, *}$, Robi Pebriansyah ${ }^{2}$, Budi Santoso ${ }^{3}$ \\ ${ }^{1}$ Prodi Ilmu Teknik Fakultas Teknik Universitas Sriwijaya \\ ${ }^{1,2}$ Prodi Rekayasa Sistem Komputer Fakultas Komputer Universitas Bina Insan, \\ ${ }^{3}$ Prodi Informatika Fakultas Komputer Universitas Bina Insan \\ 1,2,3 Jl. Jend Besar HM Soeharto KM 13 Kel. Lubuk Kupang Kota Lubuklinggau, Prov. Sumatera \\ Selatan \\ *Corresponding Author: mas.arifin@univbinainsan.ac.id
}

\begin{abstract}
Water is an important element that becomes the need of every human being, in the service provider company Clean water control of water usage is still a problem because no system provides information on the use of water on the customer side, especially in the BLUD UPT SPAM Musi Rawas. Customers also find it difficult to see the amount of bills in realtime so that if the billing information has been presented then the customer can adjust the use of the water. This system will use a Waterflow Sensor to read the water flow which will then be converted to Digital data in the form of computer bits that will be processed by Arduino and then sent to the Server to be seen by the Clean Water Service Provider in this case the BLUD UPT SPAM Musi Rawas and customers.
\end{abstract}

Keywords - Internet of things (IoT), Arduino, Information System, Water Control.

Intisari-Air merupakan unsur penting yang menjadi kebutuhan setiap manusia, pada perusahaan penyedia layanan Air bersih kontrol penggunaan air masih menjadi masalah karena belum ada sistem yang menyediakan informasi penggunaan Air pada sisi Pelanggan khususnya di BLUD UPT SPAM Kabupaten Musi Rawas. Pelanggan juga kesulitan untuk melihat jumlah tagihan secara realtime sehingga jika informasi tagihan tersebut sudah tersaji maka pelanggan dapat mengatur penggunaan Airnya. Sistem ini akan menggunakan Waterflow Sensor untuk membaca aliran air yang kemudian akan di konversikan ke data Digital berupa bit komputer yang akan di proses oleh Arduino kemudian di kirimkan ke Server untuk dapat di lihat oleh Penyedia Jasa Air bersih dalam Hal ini BLUD UPT SPAM Kabupaten Musi Rawas dan Pelanggan.

Kata kunci-Internet of things (IoT), Arduino, Sistem Informasi, Penggunaan Air Bersih.

\section{Pendahuluan}

IoT (Internet of things) merupakan sebuah konsep yang bertujuan untuk memperluas manfaat dari konektivitas internet yang tersambung secara terus menerus. Adapun yang memiliki kemampuan seperti berbagi data, remote control, dan sebagainya melalui sensor yang tertanam dan selalu aktif [1].

Salah satu penelitian yang membahas penerapan IoT (Internet of things) untuk memantau penggunaan air rumah tangga dengan menggunakan android sebagai media monitoringnya dan Mikrokontroler NODEMCU sebagai perangkat proses data Penelitian ini 
hanya membahas cara memonitoring penggunaan air dari sisi pengguna [2].

Kemudian Koneksi Database dari perangkat sensor dan arduino pada penelitian yang berjudul Perancangan Sistem Monitoring Perkembangan Balita Menggunakan Mikrokontroler Atmega328p Terintegrasi Dengan Database Mysql [7], setiap hasil sensor dimasukkan ke dalam field yang berbeda di dalam database sehingga mempermudah dalam menyusun program.

Belum adanya sistem yang mampu monitoring penggunaan Air pada Pelanggan dan Penentuan Harga air khususnya di BLUD UPT SPAM Kabupaten Musi Rawas menyulitkan bagi petugas dalam mengumpulkan data penggunaan air pada Pelanggan sehingga sering terjadi kesalahan input Harga yang harus di bayar oleh Pelanggan. Dengan menggunakan Sistem Informasi Penggunaan Air Rumah Tangga yang di lengkapi dengan teknologi IoT di harapkan dapat mempermudah petugas dalam memonitoring penggunaan Air dan memberikan Informasi yang akurat ke Pelanggan dalam penggunaan yang sudah mereka gunakan.

\section{LANDASAN TEORI}

\section{A. Internet of things (IoT)}

Teknologi IoT adalah sistem fisik cyber atau jaringa dari jaringan yang terdiri dari banyak objek/things dan sensor/akuator yang saling terhubung dalam jaringan internet yang sangat besar dan digunakan sebagai sarana untuk mengalirkan data yang dihasilkan oleh sensor/things. Melalui IoT data akan dikumpulkan, dipertukarkan dan dianalisis untuk mendapatkan informasi yang bernilai terkait hubungan antara things tersebut [3].

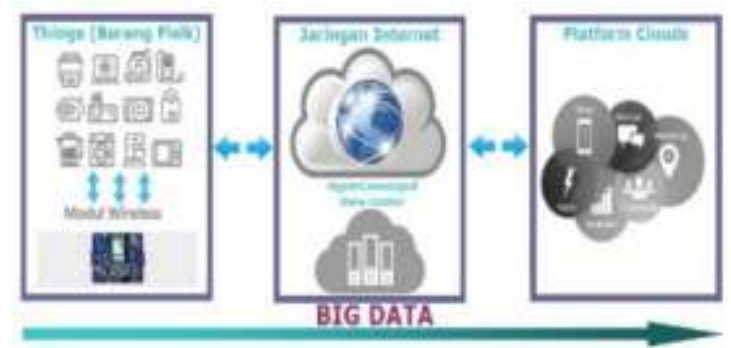

Gambar 1. Konsep Internet of things [3]

\section{B. Arduino}

Arduino adalah arduino board yang mengunakan mikrokontroler Atmega 328. Arduino memiliki 14 pin digital (6 pin dapat digunakan sebgai output PWM), 6 input analog, sebuah $16 \mathrm{MHZ}$ osilator Kristal, sebuah koneksi USB, sebuah konektor sumber tegangan, sebuah header ICSP, dan sebuah tombol reset. Arduino UNO memuat segala hal yang dibutuhkan untuk mendukung sebuah mikrokontroler. Hanya dengan menghubungkannya kesebuah komputer melalui USB atau memberikan tegangan DC dari baterai atau adaptor AC ke DC sudah dapat membuahnya bekerja. Arduino UNO mengunakan Atmega 16U2 yang diprogramkan komunikasi serial ke komputer melalui port USB [4].

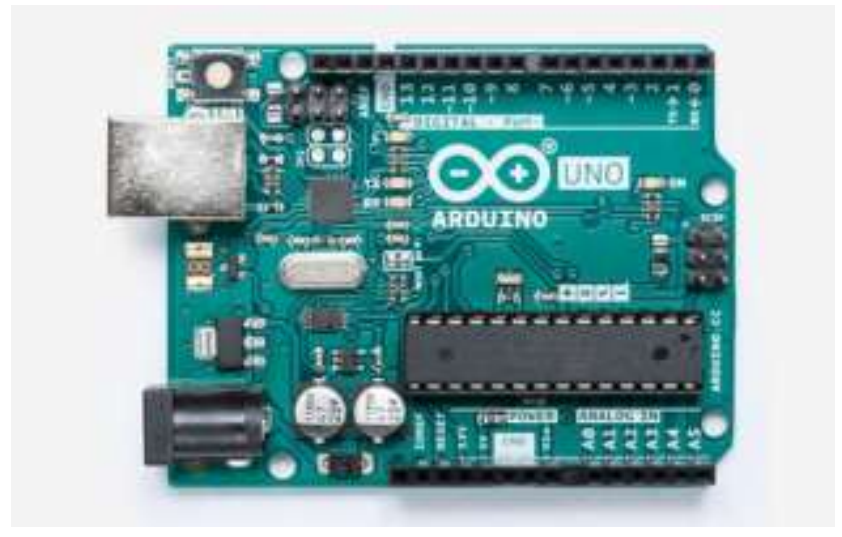

Gambar 2. Arduino Rev 3 Board [8]

\section{Ethernet Shield}

Ethernet Shield adalah modul yang digunakan untuk mengkoneksikan Arduino dengan internet menggunakan kabel (Wired). Arduino Ethernet Shield dibuat berdasarkan pada Wiznet W5100 ethernet chip. Wiznet W5100 menyediakan IP untuk TCP dan UDP, yang mendukung hingga 4 socket secara simultan. Untuk menggunakanya dibutuhkan library Ethernet dan SPI. Dan Ethernet Shield ini menggunakan kabel RJ-45 untuk mengkoneksikanya ke Internet, dengan integrated line transformer dan juga Power over Ethernet [5].

Ethernet Shield bekerja dengan cara memberikan layanan IP pada arduino dan pc agar dapat terhubung ke internet. Cara menggunakan cukup mudah yaitu hanya dengan menghubungkan Arduino Ethernet Shield 
dengan board Arduino lalu akan disambungkan ke jaringan internet. Cukup memasukkan module ini ke board Arduino, lalu menghubungkannya ke jaringan ineternet dengan kabel RJ-45, maka Arduino akan terkoneksi langsung ke internet. Dan untuk menggunakanya, tentu saja kita harus menyetting IP pada module dan pc internet agar dapat terhubung satu sama lain [5].

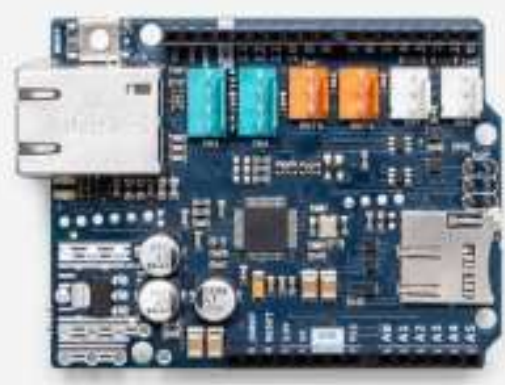

Gambar 3. Ethernet Shield [9]

\section{Waterflow Sensor}

Water flow sensor merupakan sebuah perangkat sensor yang digunakan untuk mengukur debit fluida. Biasanya flow sensor adalah elemen (bagian) yang dilakukan flow meter [6].

Tipe flow sensor yang digunakan merupakan mechanical flow sensor. Sensor tipe ini memiliki rotor dan tranducer hall-effect didalamnya untuk mendeteksi putaran rotor ketika fluida melewatinya. Putaran tersebut akan menghasilkan pulsa digital yang banyaknya sebangding dengan banyaknya fluida yang mengalir melewatinya [6].

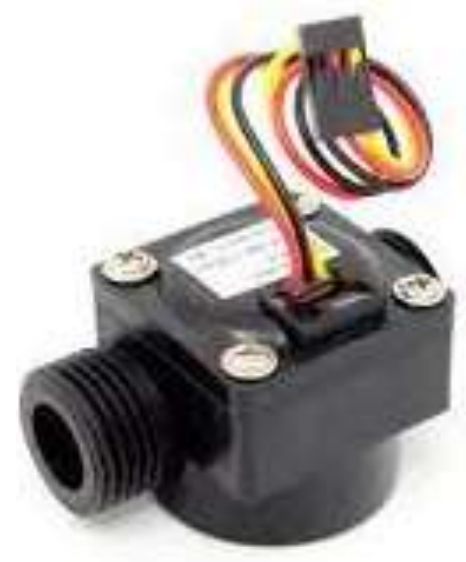

Gambar 4. Waterflow Sensor tipe YF-S201[10]
III. MEtode PENELITIAN

Metode yang di gunakan untuk mencapai hasil yang di tuju pada penelitian ini di bagi menjadi 2 tahap yaitu Analisis Kebutuhan Sistem dan Desain Sistem.

\section{A. Analisis Kebutuhan}

Dari hasil analisis kebutuhan, komponen yang akan di gunakan untuk membangun Prototype Internet of things pada Sistem Informasi Penggunaan Air Rumah Tangga adalah :

1. Arduino Uno, untuk memproses Data Analog dari Sensor ke Data Digital

2. Ethernet Shield, sebagai perangkat trasnmisi ke server

3. Waterflow Sensor, komponen penghitung debit air

4. Pompa, digunakan untuk menciptakan kondisi air mengalir agar dapat terbaca oleh Sensor

5. LCD untuk menampilkan kondisi realtime air yang sedang mengalir

6. Halaman monitoring untuk menyajikan Sistem Informasi penggunaan Air

\section{B. Desain Sistem}

1. Desain Perangkat Keras

Desain dan cara kerja Perangkat Keras pada penelitian ini dapat dilihat pada Gambar 5.

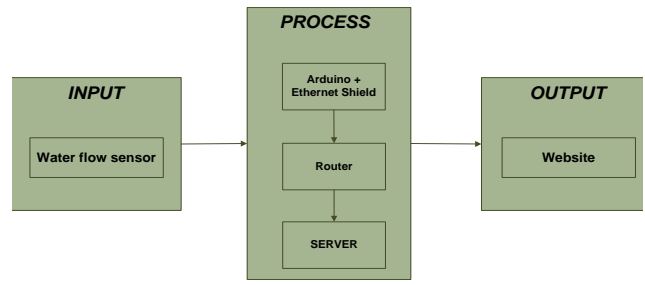

Gambar 5. Diagram Blok Sistem

Pada bagian Input sensor akan membaca jumlah debit air yang masuk dengan menghitung jumlah putaran turbin yang ada pada sensor berupa data analog kemudian data analog tadi di proses oleh arduino menjadi data digital yang dapat di baca oleh websever dan di simpan di dalam database melalui ethernet shield dan router sebagai media transmisinya. Website berfungsi menampilkan data penggunaan air baik dari sisi pelanggan 
maupun penyedia layanan dan sebagai media input untuk memasukkan harga air.

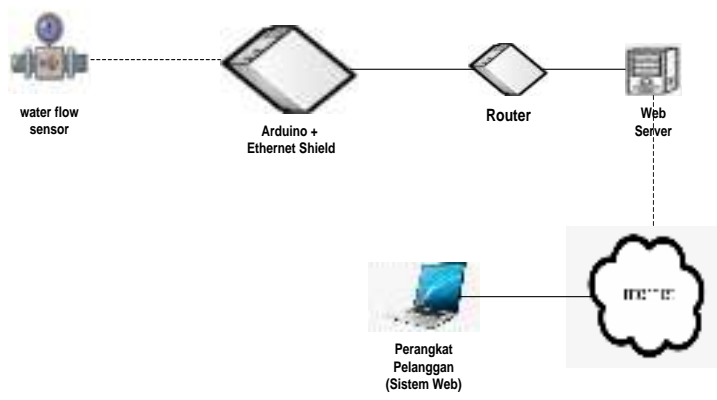

Gambar 6. Desain Jaringan

Arduino akan terhubung secara lokal dengan router dan web server dan web server akan terhubung ke internet untuk menyajikan data hasil sensor.

Tabel 1. Desain Pengalamatan IP

\begin{tabular}{|c|c|c|c|}
\hline No & Perangkat & IP Address & Keterangan \\
\hline 1 & $\begin{array}{l}\text { Ethernet } \\
\text { Shield pada } \\
\text { Arduino }\end{array}$ & 192.168 .10 .1 & $\begin{array}{l}\text { IP Address dari } \\
\text { Ethernet Shield } \\
\text { pada Arduino }\end{array}$ \\
\hline 2. & Router & 192.168 .10 .2 & $\begin{array}{l}\text { IP Address dari } \\
\text { Router }\end{array}$ \\
\hline 2 & Web Server & 192.168 .10 .3 & $\begin{array}{l}\text { IP Address dari } \\
\text { Web Server } \\
\text { yang terhubung } \\
\text { ke router }\end{array}$ \\
\hline & & $\begin{array}{l}\text { ISP (Internet } \\
\text { Service } \\
\text { Provider) }\end{array}$ & $\begin{array}{l}\text { IP Address } \\
\text { yang terhubung } \\
\text { ke jaringan } \\
\text { internet }\end{array}$ \\
\hline
\end{tabular}

\section{Desain Perangkat Lunak}

Use Case dari sistem dapat dilihat pada Gambar 7 :

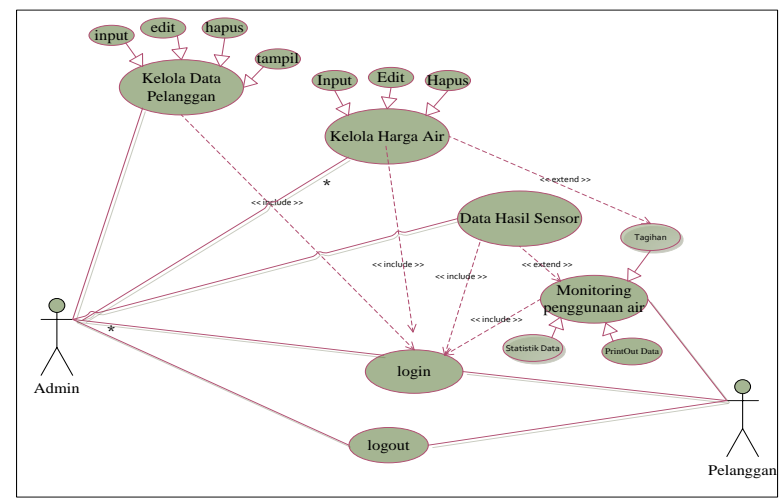

Gambar 7. Use Case Diagram Sistem

Adapun desain tabel dari database monitoring penggunaan air menggunakan IoT (Internet of things) adalah sebagai berikut :
Tabel 2. Desain Tabel Admin

\begin{tabular}{|c|c|c|c|c|}
\hline No & Field & Type & Size & Keterangan \\
\hline 1 & id_admin & Int & 11 & Id Admin \\
\hline 2 & nama_admin & Varchar & 40 & Nama admin \\
\hline 3 & email_admin & Varhar & 40 & Email admin \\
\hline 4 & username & Varchar & 60 & $\begin{array}{l}\text { Username } \\
\text { login }\end{array}$ \\
\hline 5 & password & Varchar & 100 & Password login \\
\hline
\end{tabular}

Tabel admin berisi id admin, nama admin, email yang daat di hubungi, username dan password admin yang akan digunakan untuk login kehalaman admin.

Tabel 3. Desain Tabel Pelanggan

\begin{tabular}{ccccl}
\hline No & \multicolumn{1}{c}{ Field } & Type & Size & Keterangan \\
\hline $\mathbf{1}$ & id_pelanggan & Int & 11 & Id pelanggan \\
$\mathbf{2}$ & nama_pelanggan & Varchar & 50 & $\begin{array}{l}\text { Nama } \\
\text { pelanggan }\end{array}$ \\
$\mathbf{3}$ & email_pelanggan & Varhar & 40 & $\begin{array}{l}\text { Email } \\
\text { pelanggan }\end{array}$ \\
$\mathbf{4}$ & no_tlp & Varchar & 15 & $\begin{array}{l}\text { Nomor Telp } \\
\text { pelanggan } \\
\text { alamat } \\
\text { pelanggan }\end{array}$ \\
$\mathbf{5}$ & Alamat & Text & - & $\begin{array}{l}\text { Username } \\
\text { login }\end{array}$ \\
$\mathbf{6}$ & Username & Varchar & 60 & Password \\
$\mathbf{7}$ & Password & Varchar & 100 & $\begin{array}{l}\text { login } \\
\text { Status } \\
\text { pelanggan }\end{array}$ \\
$\mathbf{8}$ & status_pelanggan & Varchar & 10 & \\
\hline
\end{tabular}

Pada tabel database pelanggan berisi informasi id pelanggan, nama pelanggan email, nomor telepon, alamat, status pelanggan, username dan password pelanggan untuk login ke halaman pelanggan.

Tabel 4. Desain Tabel Penggunaan Air

\begin{tabular}{|c|c|c|c|c|}
\hline No & Field & Type & $\begin{array}{c}\mathrm{Siz} \\
e\end{array}$ & $\begin{array}{c}\text { Keteran } \\
\text { gan }\end{array}$ \\
\hline 1 & id_penggunaan & Int & 11 & $\begin{array}{l}\text { Id } \\
\text { pengguna } \\
\text { an }\end{array}$ \\
\hline 2 & id_pelanggan & Int & 11 & $\begin{array}{l}\text { Id } \\
\text { pelangga } \\
\text { n }\end{array}$ \\
\hline 3 & $\begin{array}{l}\text { debit_penggunaa } \\
\text { n_air }\end{array}$ & Varchar & 30 & $\begin{array}{l}\text { Besar } \\
\text { pengguna } \\
\text { an air }\end{array}$ \\
\hline 4 & harga & Int & 10 & $\begin{array}{l}\text { Harga } \\
\text { Air }\end{array}$ \\
\hline 5 & tanggal_update & timesta & - & Tanggal \\
\hline
\end{tabular}




\begin{tabular}{ll}
\hline$m p$ & $\begin{array}{l}\text { update } \\
\text { data }\end{array}$ \\
\hline
\end{tabular}

Pada tabel penggunaan Air akan berisi debit penggunaan air yang sudah di gunakan pelanggan yang diambil dari data sensor, dengan id_penggunaan sebagai Primary key dan id_pelanggan sebagai Foreign Key sehingga penggunaan air dapat langsung dilihat oleh pelanggan di halaman pelanggan.

Tabel 5. Desain Tabel Harga Air

\begin{tabular}{|c|c|c|c|c|}
\hline No & Field & Type & $\begin{array}{c}\mathrm{Siz} \\
\mathrm{e}\end{array}$ & $\begin{array}{c}\text { Keteran } \\
\text { gan }\end{array}$ \\
\hline $\mathbf{1}$ & status_pelanggan & Varchar & 11 & $\begin{array}{l}\text { Status } \\
\text { Pelangga } \\
\mathrm{n}\end{array}$ \\
\hline 2 & harga & Int & 11 & $\begin{array}{l}\text { Harga } \\
\text { Air }\end{array}$ \\
\hline
\end{tabular}

Tabel harga air akan menyimpan biaya besaran penggunaan air yang akan di bayar pelanggan.

\section{Hasil dan Pengujian Sistem}

\section{A. Hasil Penelitian}

\section{Perangkat Keras}

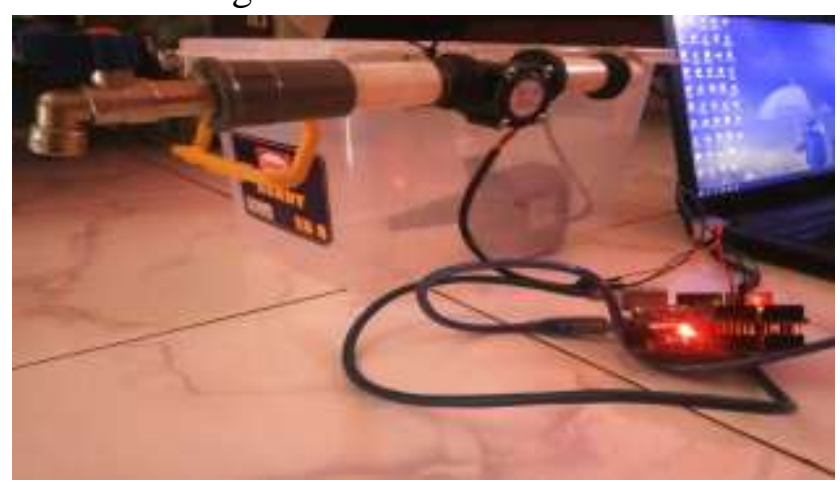

Gambar 8. Arduino dan Ethernet Shield

Arduino dan Ethernet Shield akan memproses dan mengirimkan data hasil sensor kedalam database.

Waterflow Sensor akan mengkonversi air yang mengalir menjadi data analog yang akan diproses pada Arduino. Dapat dilihat pada Gambar 9.

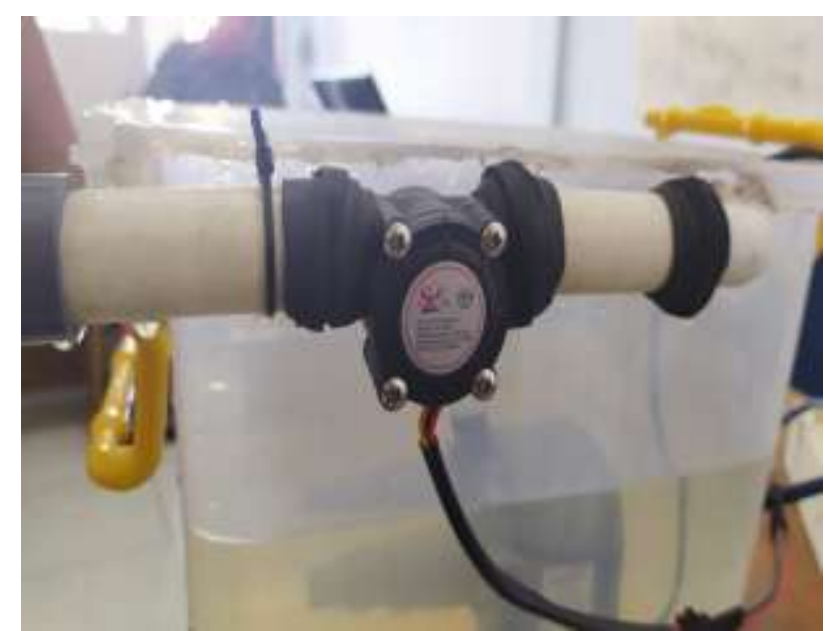

Gambar 9. Waterflow Sensor

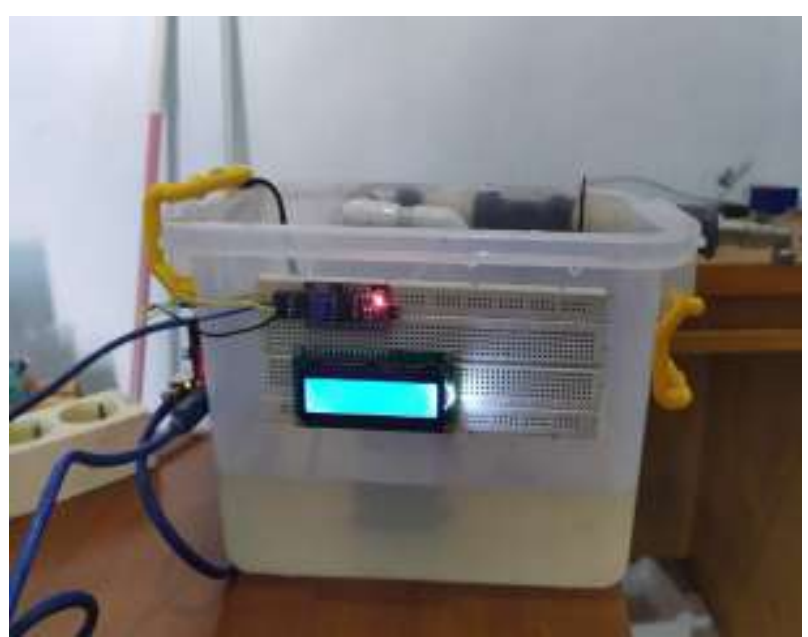

Gambar 10. Tampak muka tempat Penampungan Air

Untuk menciptakan kondisi seolah - olah pelanggan menggunakan Air maka di buat tempat penampungan Air yang di buat tergabung dengan sensor dan perangkat arduino yang teringrasi dengan ethernet shield menjadi satu kesatuan untuk mempermudah dalam pengambilan data.

\section{Perangkat Lunak}

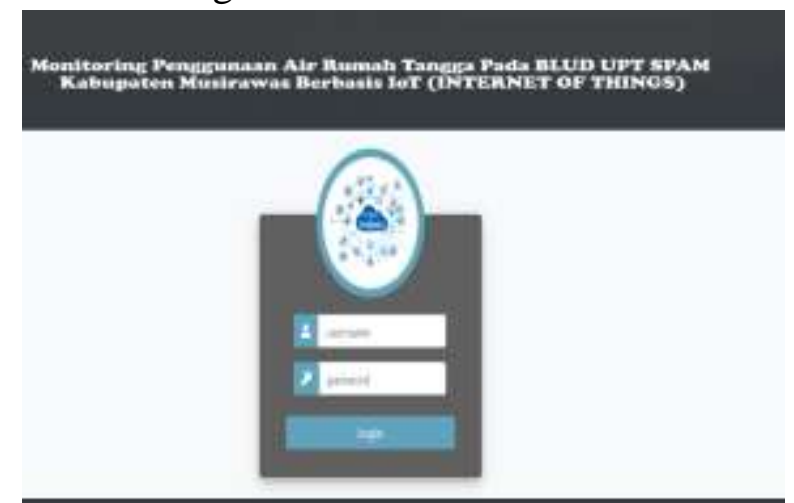

Gambar 11. Halaman Login untuk Admin dan Pelanggan 
M.A.S. Arifin, R. Pebriansyah, dan B. Santoso, Prototipe Penerapan Internet of Things pada Sistem Informasi Penggunaan Air Rumah Tangga di BLUD UPT SPAM Kabupaten Musi Rawas

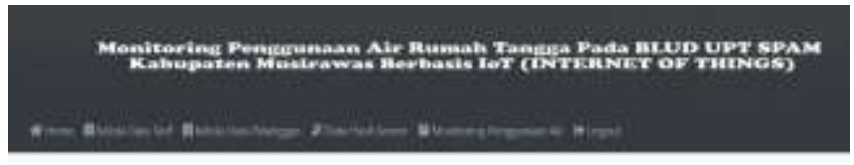

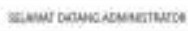

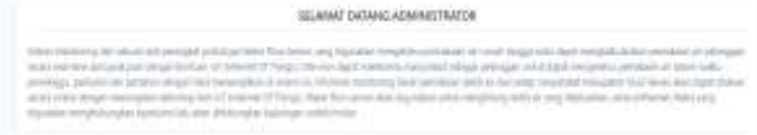

Gambar 12. Halaman Awal Admin

Setelah login admin akan diarahkan ke halaman awal admin yang berisi menu - menu untuk mengelola pelanggan, monitoring pengguaan air dan mengelola data admin.

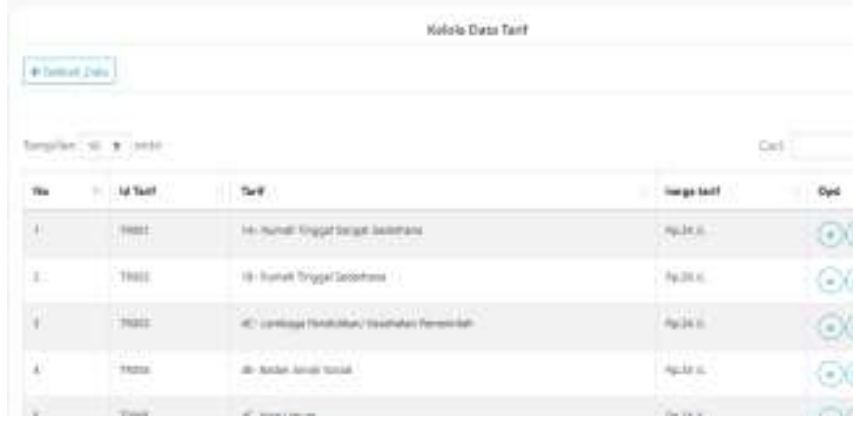

Gambar 13.Halaman Kelola Harga Air

Pada halaman kelola harga Air Admin dapat menentukan harga yang akan di kenakan ke pelanggan berdasarkan status pelanggan.
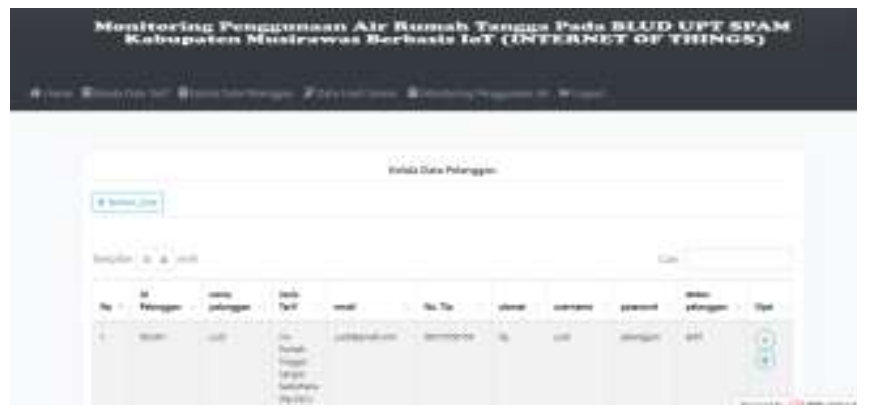

Gambar 14. Halaman Kelola Data Pelanggan

Pada halaman 14 ini admin dapat mengatur data pelanggan, baik melakukan Edit maupun Hapus pelanggan.

Setelah Login pelanggan akan diarahkan ke halaman awal pelanggan yang berisi menu menu untuk melakukan monitoring pengguna air maupung perubahan data pelanggan.
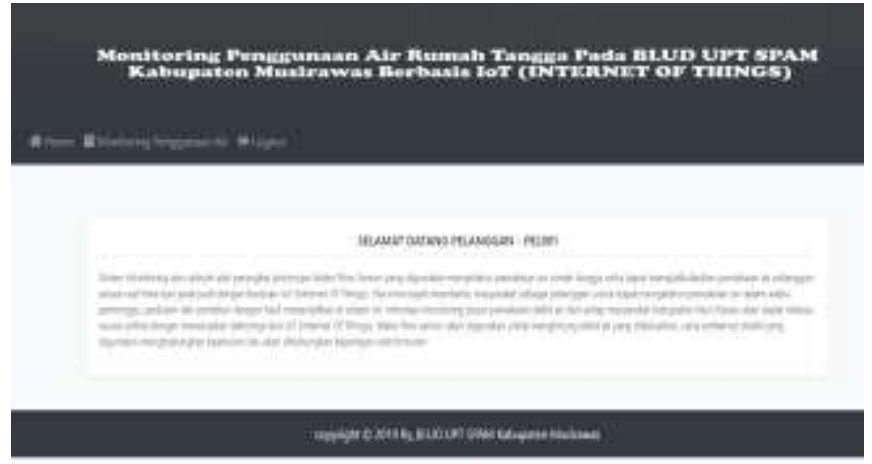

Gambar 15. Halaman Awal Pelanggan setelah Login

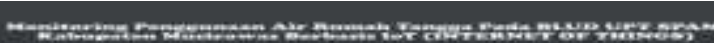

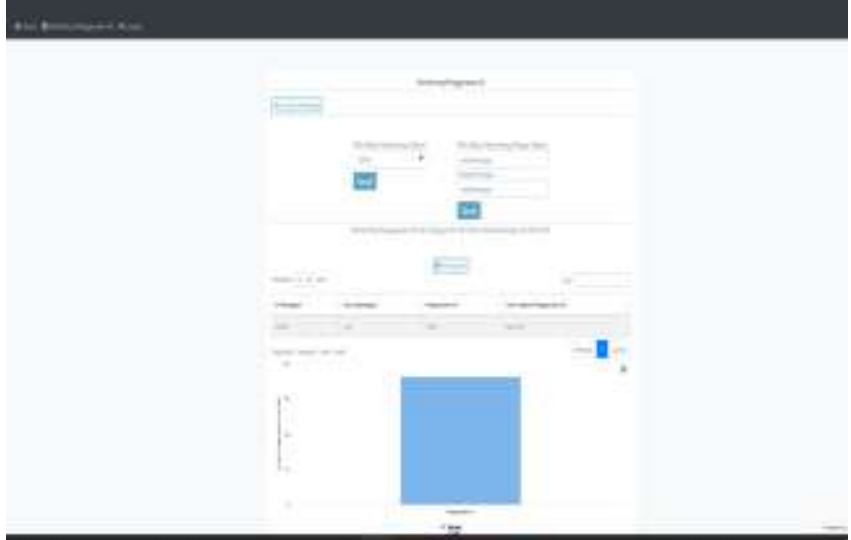

Gambar 16. Halaman Monitoring Penggunaan Air

Nriving Proygasen kir

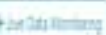

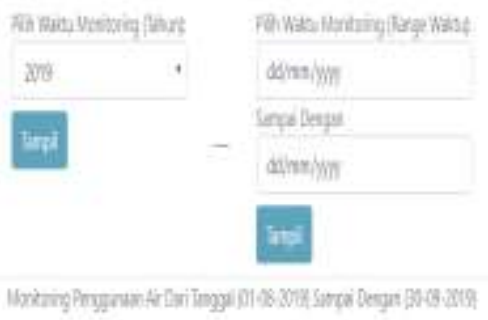

Gambar 17. Menu Pilihan waktu untuk melihat penggunaan Air

Setelah menentukan jangka waktu tanggal untuk melihat berapa banyak air yang di gunakan maka akan tempil grafik dan harga yang harus di bayar. 


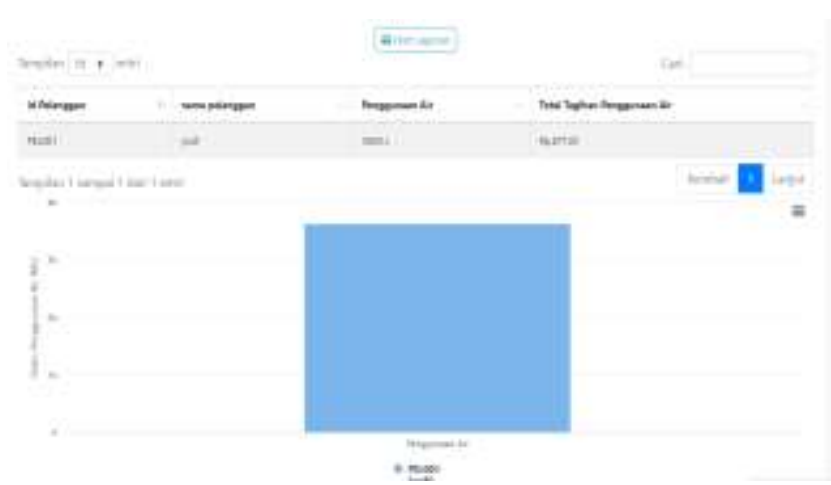

Gambar 18. Grafik dan Harga Air yang sudah di Gunakan

Pada gambar 18 adalah contoh grafik penggunaan air yang sudah masuk kedalam Database dalam contoh ini di gunakan id pelanggan PEL001.

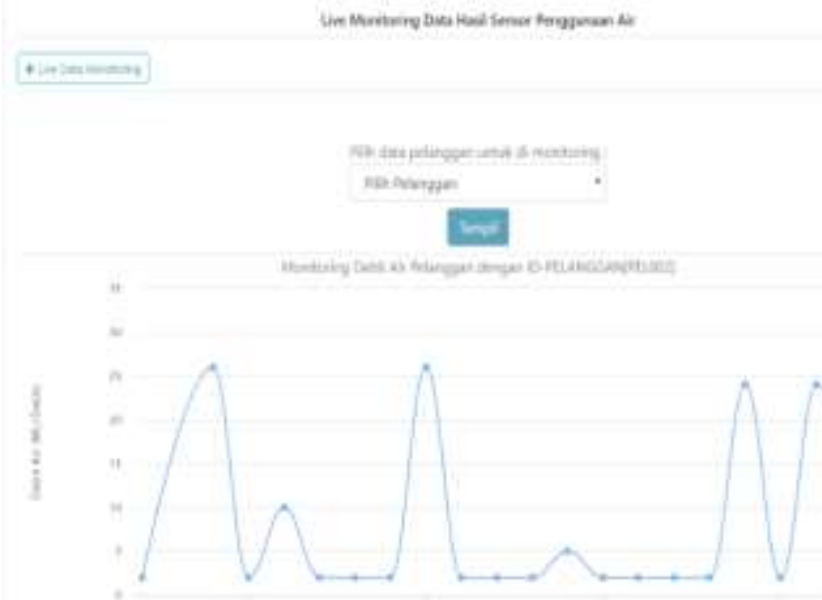

Gambar 19. Hasil Monitoring Grafik Penggunaan Air secara realtime

\section{B. Pengujian Sistem}

Pengujian dilakukan untuk melihat data yang di hasilkan oleh sensor melalui halaman terminal menggunakan software Arduino IDE dan dengan membuka aplikasi web yang sudah di buat apakah terjadi perbedaan.

Data pengujian dari gambar 20 diambil dari tampilan terminal pada arduino yang menunjukkan proses pembacaan hasil sensor.

Dari pengujian yang dilakukan pada gambar 20 dan 21 dengan membandingkan hasil yang ada di terminal serial monitor Arduino IDE dan aplikasi web, terdapat delay dalam menampilkan data hasil sensor. Dimana hasil lebih cepat keluar pada terminal serial monitor dari pada halaman website, hal ini di sebabkan oleh data yang di tampilkan pada website lebih lambat dari pada proses penyimpanan data hasil sensor ke dalam database sehingga proses tersebut yang menjadi penyebab terjadinya perbedaan waktu tampil hasil sensor pada sistem ini.

\section{coser \\ 09:12:52,391 $\rightarrow$ Debit air: 991/ortit

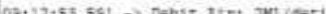 \\ $05: 12: 54.595 \rightarrow$ Debit Air: $1001 /$ detis

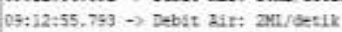

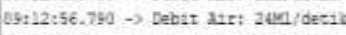 \\ 05:12:57.851 $\rightarrow$ Debit air: an/osetik \\ $09: 12: 56.879$ - Debit 21r: 1361 /dec12 \\ 09:13:00.095 $\rightarrow$ Dabir 11r: 2M1/dectib

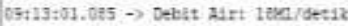

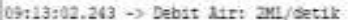

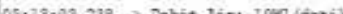

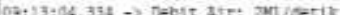 \\ 05:13:05.317 $\rightarrow$ Debit dir: suldoetil

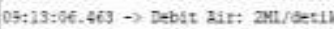 \\ 05:13:07.446 $\rightarrow$ Debir 1tr: 9a1/ dettit \\ 05:13:08.465 $\rightarrow$ Debit air: ant/detik

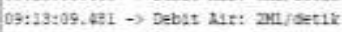 \\ 05:13:16.4ts $\rightarrow$ Dabat Bir: 13ac/derit}

Gambar 20. Pengujian Data Hasil Sensor

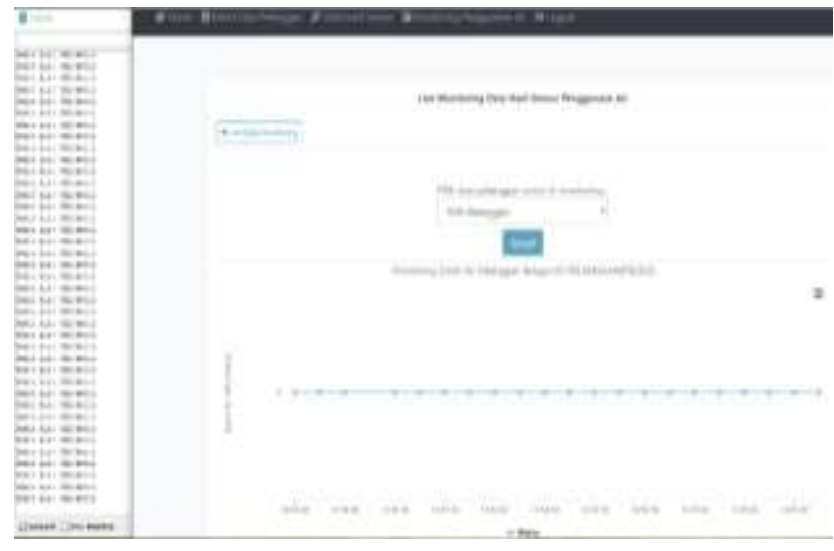

Gambar 21. Pengujian realtime jika kran air tidak di buka

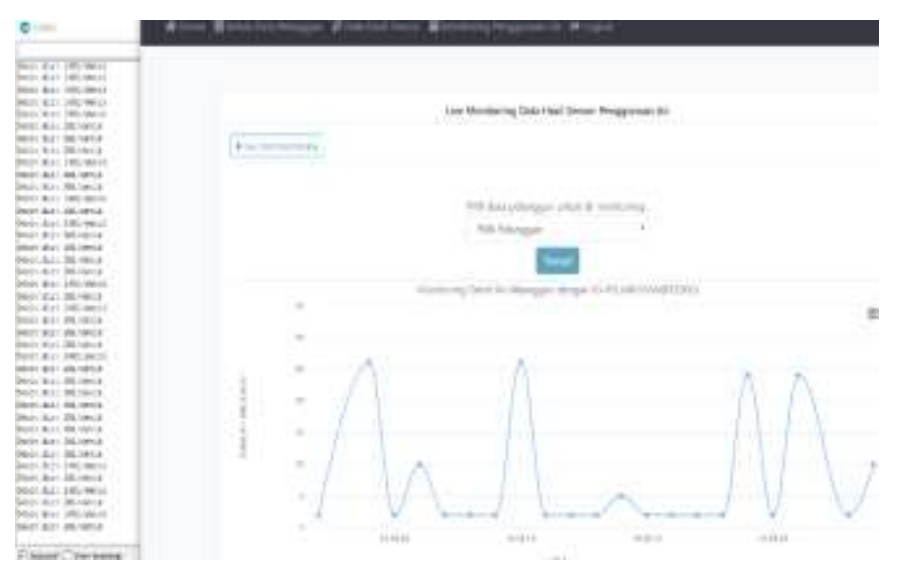

Gambar 22. Pengujian Realtime jika kran Air di Buka 


\section{KESIMPULAN DAN SARAN}

\section{A. Kesimpulan}

Kesimpulan yang dapat diambil dari penelitian ini adalah Rangkaian Sistem dan Aplikasi dapat menampilkan data dengan akurat, Sensor bekerja dengan baik dalam mengukur air yang keluar.

Jika penerapan Internet of things pada Sistem Informasi Penggunaan Air Rumah Tangga dapat di terapkan maka akan menjadi solusi bagi pelanggan untuk memonitor penggunaan air dan mempermudah pihak penyedia layanan dalam hal ini BLUD UPT SPAM Kabupaten Musi Rawas dalam mengawasi penggunaan air dan menentukan harga air.

Pada pengujian terdapat perbedaan Waktu dalam menampilkan data hasil sensor antara Serial Monitor dengan data hasil sensor yang di tampilkan di website. Hal ini terjadi karena untuk menampilkan hasil sensor di web berbarengan dengan proses penyimpanan data hasil sensor ke dalam database.

\section{B. Saran}

Saran untuk penelitian dengan tema yang sama maupun kemungkinan untuk penerapan sistem adalah Untuk penelitian selanjutnya dengan tema yang sama mungkin dapat menggunakan perangkat pemrosesan data hasil sensor yang lebih baik seperti menggunakan Raspberry Pi.

Untuk penerapan sistem ini pada kondisi sesungguhnya masih di butuhkan kajian yang mendalam khususnya untuk topologi jaringan yang akan digunakan. Kemungkinan dengan menggunakan Raspberry Pi atau perangkat lain dengan arsitektur prosessor ARM dapat meminimalisir delay dalam menampilkan Data.

\section{REFERENSI}

[1] M. A. Afrizal, "Rancang Bangun Rumah Pintar Berbasis Iot (Internet of things) Sebagai Media Pembelajaran Pada Mata Pelajaran Pemrograman, Mikroprosesor, Dan Mikrokontroller," J. Pendidik. Tek. Elektro, vol. V. 07, no. 1, pp. 79-86, 2018.
[2] D.P.A.R. Hakim, "Sistem Monitoring Penggunaan Air PDAM pada Rumah Tangga Menggunakan Mikrokontroler NODEMCU Berbasis Smartphone ANDROID," pp. 45-52, 2018.

[3] H. B. Santoso, S. Prajogo, and S. R. I. P. Mursid, "Pengembangan Sistem Pemantauan Konsumsi Energi Rumah Tangga Berbasis Internet of things (IoT)," vol. 6, no. 3, pp. 357-366, 2018.

[4] Arduino.cc, " Pengenalan Tentang Arduino Uno." Arduino.cc, 2018. Tersedia pada: https://www.arduino.cc. [Diakses: 18-Juli-2019].

[5] immersa-lab.com, " Pengertian Ethernet Shield dan Cara Kerja." 2018. tersedia pada :https://www.immersalab.com/pengertian-ethernet-shield-dancara-kerjanya.html [Diakses :20-Juli2019].

[6] indo-ware.com, "Waterflow Sensor". 2019. tersedia pada : https://indoware.com/produk-334-waterflow-sensoryfs201.html [Diakses pada 20-Juli-2019].

[7] R. Kurniawan, "Perancangan Sistem Monitoring Perkembangan Balita Menggunakan Mikrokontroler Atmega328p Terintegrasi Dengan Database Mysql Di Posyandu Pian Raya Kabupaten Musirawas," Vol. 3 No. 2 pp.72 - 81, Desember 2018

[8] store.arduino.cc "Arduino Rev 3 Picture". 2019 tersedia pada https://store.arduino.cc/usa/arduino-unorev3 [Diakses pada 20-Juli -2019]

[9] store.arduino.cc "Ethernet Shield Picture". 2019 tersedia pada https://store.arduino.cc/usa/arduinoethernet-shield-2 [Diakses pada 20-Juli 2019]

[10] instructables.com "Waterflow Sensor". 2019 tersedia pada : https://www.instructables.com/id/How-to- 
Jurnal Sustainable: Jurnal Hasil Penelitian dan Industri Terapan Vol. 08, No. 02, hal. 82 - 90, Oktober 2019
ISSN 2615-6334 (Online)

ISSN 2087-5347 (Print)

Use-Water-Flow-Sensor-Arduino-Tutorial/

[Diakses pada 20-Juli -2019] 